\title{
FAKTOR-FAKTOR YANG BERHUBUNGAN DENGAN KONSUMSI SOPI PADA REMAJA DI KOTA LILIBA KUPANG
}

\author{
${ }^{1}$ Intje Picauly, ${ }^{2}$ Emanuel SB. Lewar, ${ }^{3}$ Sabina Gero \\ ${ }^{1}$ Program Studi Ilmu Kesehatan Masyarakat, FKM Undana \\ ${ }^{2}$ Jurusan Kebidanan, Stikes Maranatha Kupang \\ ${ }^{3}$ Prodi Keperawatan Poltekes Kemenkes, Kupang
}

\begin{abstract}
ABSTRAK
SOPI adalah produk yang dihasilkan dengan cara fermentasi dengan menggunakan yeast (yeast / saccaromyces cereviceae), pada bahan yang mengandung pati. Minuman keras tergolong zat adiktif karena dapat menimbulkan kecanduan (addiction) dan ketergantungan (dependencies). Jumlah pengguna narkotika dan minuman keras di Indonesia sebagian besar berasal dari pelajar SLTP, SLTA, dan Perguruan Tinggi yang mencapai $70 \%$, sedangkan lulusan SD hanya $30 \%$, dan sebagian besar dari kalangan menengah ke atas. Remaja yang mengonsumsi minuman beralkohol sebanyak 4,9\%. Namun pada tahun 2014, berdasarkan penelitian yang dilakukan GeNAM jumlahnya melonjak menjadi $23 \%$ dari total jumlah remaja yaitu sekitar 63 juta orang atau sekitar 14,4 juta orang. Prevalensi peminum alkohol di Provinsi Nusa Tenggara Timur mencapai 17,6\%. Angka ini jauh lebih tinggi dari angka prevalensi nasional sebesar 3,2\%. Sedangkan di kota kupang sendiri peminum alkohol mencapai $12,2 \%$. Jumlah tindak pidana akibat konsumsi soro pada tahun 2011 sebanyak 287 kasus, tahun 2012 sebanyak 291 kasus, tahun 2013 sebanyak 212 kasus, 2014 sebanyak 205 kasus, 2015 sebanyak 191 kasus dan 2016 (hingga Agustus 2016). ) sebanyak 175 kasus. Tujuan penelitian ini adalah untuk menganalisis faktor-faktor yang berhubungan dengan konsumsi sopi pada remaja di Kelurahan Liliba Kota Kupang. Penelitian ini menggunakan pendekatan kuantitatif dengan metode cross sectional. Pengambilan sampel menggunakan teknik purposive sampling dengan jumlah sampel sebanyak 48 responden (remaja). Hasil penelitian menunjukkan bahwa terdapat hubungan antara konsumsi soro pada remaja dengan faktor predisposisi, faktor pendukung dan faktor penguat: $p<0,05 ; p=0,049$ (pengetahuan), $\mathrm{p}<0,05 ; \mathrm{p}=0,004$ (tingkat pendidikan), $\mathrm{p}<0,05, \mathrm{p}=0,788$ (sikap), $\mathrm{p}>0,05 ; \mathrm{p}=$ 0,499 (jenis kelamin), $\mathrm{p}=, \mathrm{P}<0,05 ; \mathrm{p}=0,016$ (jarak), $\mathrm{p}<0,05 ; \mathrm{p}=0,000$ (pemasaran), $\mathrm{p}<0,05 ; \mathrm{p}$ $=0,000$ (dukungan orang tua), $\mathrm{p}<0,05 ; \mathrm{p}=0,000$ (dukungan lingkungan), $\mathrm{p}<0,05 ; \mathrm{p}=0,052$ (asosiasi), $\mathrm{p}<0,05 ; \mathrm{p}=0,000$ (kontrol orang tua). Kesimpulan dari pemodelan persamaan regresi: Kepercayaan berpengaruh positif terhadap konsumsi soro pada remaja, bahwa setiap penurunan 1 satuan kepercayaan akan menurunkan konsumsi soro pada remaja di Kelurahan Liliba Kota Kupang sebesar 3,081. Hasil probabilitas kepercayaan terkait konsumsi soro adalah 97\% pada remaja di Kelurahan Liliba Kota Kupang.
\end{abstract}

Kata Kunci : Faktor Predisposisi, Faktor Pendukung, Faktor Penguat, Konsumsi Sopi, Anak Remaja 


\title{
RELATED FACTORS WITH THE CONSUMPTION OF SOPI IN ADOLESCENT IN THE LILIBA KUPANG CITY
}

\author{
${ }^{1}$ Intje Picauly, ${ }^{2}$ Emanuel SB. Lewar, ${ }^{3}$ Sabina Gero \\ ${ }^{1}$ Public Health Study Program, FKM Undana \\ ${ }^{2}$ Department of Midwifery, Stikes Maranatha Kupang \\ ${ }^{3}$ Nursing study program Poltekes Kemenkes, Kupang
}

\begin{abstract}
Liquor is a product produced by fermentation by using yeast (yeast / saccaromyces cereviceae), on a starch-containing material. Liquor is classified into addictive substances because it can cause addiction (addiction) and dependence (dependencies). The number of narcotics and liquor users in Indonesia is mostly from the junior high school, senior high school, and college students, which reaches $70 \%$, while only $30 \%$ of elementary school graduates, and most of them are from middle to upper class. The number of adolescents consuming alcoholic drinks was $4.9 \%$. But in 2014, based on research conducted GeNAM number jumped to $23 \%$ of the total number of teens that is about 63 million people or about 14.4 million people. The prevalence of alcohol drinkers in East Nusa Tenggara Province reached $17.6 \%$. This figure is much higher than the national prevalence rate of $3.2 \%$. While in the city kupang own drinkers reach $12.2 \%$ alcohol. The number of criminal acts due to consumption of soro in 2011 was 287 cases, in 2012 as many as 291 cases, in 2013 as many as 212 cases, 2014 as many as 205 cases, 2015 as many as 191 cases and 2016 (until August) as many as 175 cases. The research problem is how the relation of knowledge factor, belief and attitude toward consumption of sopi in adolescent in Kelurahan Liliba Kota Kupang. The purpose of this study is to analyze the factors associated with consumption of sopi in adolescents in Kelurahan Liliba Kota Kupang. This research use quantitative approach with cross sectional method. Sampling using purposive sampling technique with the number of samples of 48 respondents (teenagers). The results showed that there was a correlation between soro consumption in adolescent with predisposing factor, supporting factor and reinforcing factor: $\mathrm{p}$ $<0,05 ; \mathrm{p}=0,049$ (knowledge), $\mathrm{p}<0,05 ; \mathrm{p}=0,004$ (education level), $\mathrm{p}<0,05, \mathrm{p}=0,788$ (attitude), $\mathrm{p}>0,05 ; \mathrm{p}=0,499$ (gender), $\mathrm{p}=, \mathrm{P}<0.05 ; \mathrm{p}=0.016$ (distance), $\mathrm{p}<0,05 ; \mathrm{p}=0,000$ (marketing), $\mathrm{p}$ $<0,05 ; \mathrm{p}=0,000$ (parental support), $\mathrm{p}<0,05 ; \mathrm{p}=0.000$ (environmental support), $\mathrm{p}<0.05 ; \mathrm{p}=$ 0.052 (association), $\mathrm{p}<0,05 ; \mathrm{p}=0,000$ (parental control). Conclusion of regression equation modeling: Trust gives positive relationship to soro consumption in adolescent, that every decrease of 1 unit of trust will decrease consumption of soro in adolescent in Liliba urban of Kupang city equal to 3,081. The results of trust probability related to consumption of soro is $97 \%$ in adolescents in Kelurahan Liliba Kota Kupang.
\end{abstract}

Keywords: Predisposition Factor, Supporting Factor, Strengthening Factor, Sopi Consumption, Teenagers. 


\section{PENDAHULUAN}

Konsumsi minuman keras yang berlebihan dapat menyebabkan ketergantungan, minuman keras berdampak negatif dalam kehidupan sosial di masyarakat. Individu yang sudah sampai pada fase penyalahgunaan dan ketergantungan miras dapat berperilaku anti sosial seperti mencuri, suka berkelahi dan marah-marah, acuh dan apatis terhadap permasalahan dan kondisi sosialnya, hingga berdampak bagi kesehatannya yaitu mengalami gangguan perkembangan otak, bunuh diri dan depresi, kehilangan memori, risiko tinggi terhadap perilaku seksual, kecanduan, pengambilan keputusan terganggu, prestasi akademis yang buruk, kekerasan, dan kecelakaan kendaraan. (Dariyo, 2004).

Penggunaan minuman keras yang berakibat buruk menyebabkan kurang lebih 3,3 juta kematian per tahunnya (5,9\% total dari seluruh kematian), dan 5,1\% beban global penyakit berhubungan dengan konsumsi minuman keras (WHO, 2014). Berdasarkan hasil survei Dinas Penelitian dan Pengembangan (Dislitbang) Polri memperlihatkan bahwa pemakai narkotika dan minuman keras di Indonesia secara nasional terbanyak dari golongan pelajar, baik SLTP, SLTA, maupun mahasiswa, yang jumlahnya mencapai $70 \%$, sedangkan yang lulusan SD hanya $30 \%$, dan sebagian besar dari mereka berasal dari golongan menengah ke atas (Santrock, 2013). Berdasarkan riset kesehatan dasar (Riskesdas) Kementerian Kesehatan Republik Indonesia, pada 2007 jumlah remaja pengonsumsi minuman beralkohol masih di angka 4,9 persen. Tapi pada 2014, berdasarkan hasil riset yang dilakukan GeNAM jumlahnya melonjak hingga angka 23 persen dari total jumlah remaja saat ini sekitar 63 juta jiwa atau sekitar 14,4 juta orang. Secara umum prevalensi peminum alkohol di Prov NTT adalah 17.6\%. Angka ini jauh lebih tinggi dari angka prevalensi nasional (3.2\%). Sedangkan di kota kupang pervalensi peminum alkohol 12,2\% (Riskesdas, 2007).

Pengaruh minuman keras (soro), yang meningkatkan kriminalitas, terutama jenis kejahatan pemalakan, kekerasan, penganiayaan, pengeroyokan, pembunuhan, perbuatan asusila dan kekerasan dalam rumah tangga (KDRT) di Kota Kupang terbilang tinggi. Dari hasil pengambilan data awal di Polresta Kota Kupang diketahui jumlah tindak pidana pada tahun 2011 sebanyak 287 kasus, tahun 2012 sebanyak 291 kasus, tahun 2013 sebanyak 212 kasus, tahun 2014 sebanyak 205 kasus, tahun 2015 sebanyak 191 kasus dan tahun 2016 (sampai 
bulan agustus) sebanyak 175 kasus. Data ini menunjukan bahwa dari tahun ke tahun kriminalitas di Kota Kupang semakin meningkat. Dari latar belakang diatas, maka peneliti peneliti tertarik untuk melakukan penelitian dengan judul "faktor yang berhubungan dengan konsumsi sopi pada remaja di Kelurahan Liliba Kota Kupang.

\section{METODELOGI PENELITIAN}

Penelitian ini menggunakan pendekatan kuantitatif dengan metode cross sectional dengan cara pendekatan random sampling. Studi cross sectional dalam penelitian dimaksud untuk mempelajari korelasi faktor predisposisi, pemungkin dan penguat dengan konsumsi sopi rote (soro) pada remaja di Kelurahan Liliba Kota Kupang. Populasi dalam penelitian ini semua remaja yang tinggal di Kelurahan Liliba. Berdasarkan data yang di ambil jumlah remaja sebanyak 3.308 orang dari umur 11-20 tahun. Sampel dalam penelitian ini sebanyak 48 responden (remaja). Instrumen dalam penelitian ini adalah kuesioner. Data yang telah dikumpulkan dianalisis secara univariat menggunakan distribusi frekuensi bivariat menggunakan uji statistik chi-square (X2) dan multivariat menggunakan regresi logistik berganda dengan menggunakan program analisis statistik.

\section{HASIL DAN PEMBAHASAN}

\section{A. Karaktekristik Responden}

Tabel 1. Karaktekristik Responden Berdasarkan Umur dan Jenis Kelamin

\begin{tabular}{ccc}
\hline Variabel & Jumlah & Presentase (\%) \\
\hline Umur & 2 & 4 \\
14 Tahun & 2 & 4 \\
15 Tahun & 2 & 6 \\
16 Tahun & 7 & 15 \\
17 Tahun & 10 & 21 \\
18 Tahun & 15 & 31 \\
19 Tahun & 9 & 19 \\
20 Tahun & 48 & 100 \\
\hline Total & 43 & 90 \\
Jenis Kelamin & 5 & 10 \\
Laki-Laki & 48 & 100 \\
Perempuan & & \\
\hline Total & & . \\
\hline
\end{tabular}

Tabel diatas menunjukan bahwa responden lebih banyak berada pada umur 17 tahun sampai 20 tahun dengan presentasi $>85,4 \%$. Dalam penelitian ini sebagian besar responden (90\%) berjenis kelamin laki-laki. 


\section{B. Faktor Predisposisi (Pengetahuan, Pendidikan, Tradisi, Kepercayaan, Jenis Kelamin dan Sikap)}

Hasil penelitian menunjukan bahwa $60 \%$ responden yang mempunyai pengetahuan tentang soro kurang baik namun tetap mengkonsumsi soro. Hasil uji Chi-Square menunjukan bahwa terdapat hubungan yang nyata $(\mathrm{p}<0,05 ; \mathrm{p}=0,049)$ antara konsumsi soro dengan faktor pengetahuan. Hasil penelitian ini sejalan dengan penelitian Verdian Nendra Dimas Pratama mengenai Perilaku remaja pengguna minuman keras tahun 2013, menunjukan bahwa mayoritas tingkat pengetahuan remaja tentang minuman keras termasuk kategori baik yaitu 20 $(46,5 \%)$ responden. Hasil tersebut berkaitan dengan baiknya pemahaman remaja tentang soro. Hasil penelitan juga sejalan dengan Kasiha N, pengetahuan remaja tentang dampak mengkonsumsi minuman keras (2007) dengan hasil penelitian dari 94 responden dengan pengetahuan baik 13 responden $(13,83 \%)$, pengetahuan cukup 35 responden $(37,23 \%)$ dan pengetahuan kurang 46 responden $(48,94 \%)$; sejalan juga dengan penelitian Miftahul J, Shanti R, Arsyad R. aspek sosial budaya pada konsumsi minuman beralkohol (tuak) (2014) hasil penelitian menunjukkan bahwa informan memahami tuak sebagai minuman tradisional beralkohol yang memiliki pengaruh positif dan negatif bagi pengonsumsinya, sejalan juga dengan Sukma Mardiyah Panggabean, analisis konsumsi tuak pada peminum tuak (2015) dengan hasil penelitian sebagian besar peminum tuak memiliki pengetahuan yang cukup mengenai tuak $(64,5 \%)$ dan sejalan juga dengan Dwi Agus Suseno, Eti Rimawati, Nurjanah, perilaku mengkonsumsi minuman keras di kalangan remaja awal (2014) dimana remaja mengetahui bahwa miras merupakan minuman yang memabukan, dimana rata-rata konsumsi miras tiap dua minggu sekali dan bisa juga seminggu sekali. Wawan (2010), menyatakan bahwa tahu yaitu mengingat suatu materi yang telah dipelajari sebelumnya termasuk mengingat kembali atau recall sesuatu yang spesifik dan seluruh bahan yang dipelajari atau rangsangan yang telah diterima, oleh karena itu tahu ini merupakan tingkat pengetahuan yang paling rendah.

Jenjang pendidikan $100 \%$ responden sudah mengkonsumsi soro dari pendidikan SD-SMA sedangkan $75 \%$ pada saat pendidikan perguruan tinggi. Hasil uji Chi-Square menunjukan bahwa ada hubungan yang nyata $(\mathrm{p}<0,05$; 
$\mathrm{p}=0,004)$ antara konsumsi soro dengan faktor jenjang pendidikan. Hasil penelitian ini sejalan dengan hasil survei Dinas Penelitian dan Pengembangan (Dislitbang)

Tabel 2. Hubungan Faktor Predisposisi (Pengetahuan, Pendidikan, Tradisi, Kepercayaan, Jenis Kelamin dan Sikap) Dengan Konsumsi Soro

\begin{tabular}{|c|c|c|c|c|c|c|c|}
\hline \multirow{3}{*}{ Faktor Predisposisi } & \multicolumn{6}{|c|}{ Konsumsi Soro } & \multirow{3}{*}{$p($ Value $)$} \\
\hline & \multicolumn{2}{|c|}{$\mathbf{Y a}$} & \multicolumn{2}{|c|}{ Tidak } & \multicolumn{2}{|c|}{ Total } & \\
\hline & $\mathbf{N}$ & $\%$ & $\mathbf{n}$ & $\%$ & $\mathbf{n}$ & $\%$ & \\
\hline \multicolumn{8}{|l|}{ Pengetahuan } \\
\hline Kurang & 3 & 60 & 2 & 40 & 5 & 100 & \multirow{2}{*}{0,049} \\
\hline Baik & 39 & 90,7 & 4 & 9,3 & 43 & 100 & \\
\hline \multicolumn{8}{|l|}{ Jenjang Pendidikan } \\
\hline PT & 18 & 75 & 6 & 25 & 24 & 100 & \multirow{2}{*}{0,004} \\
\hline SD-SMA & 24 & 100 & 0 & 0 & 24 & 100 & \\
\hline \multicolumn{8}{|l|}{ Tradisi } \\
\hline Tidak & 16 & 72,7 & 6 & 27,3 & 22 & 100 & \multirow{2}{*}{0,004} \\
\hline Ya & 26 & 100 & 0 & 0 & 26 & 100 & \\
\hline \multicolumn{8}{|l|}{ Kepercayaan } \\
\hline Tidak & 7 & 58,3 & 5 & 41,7 & 12 & 100 & \multirow{2}{*}{0,000} \\
\hline Ya & 35 & 97,2 & 1 & 2,8 & 36 & 100 & \\
\hline \multicolumn{8}{|l|}{ Sikap } \\
\hline Kurang Baik & 9 & 90 & 1 & 10 & 10 & 100 & \multirow{2}{*}{0,788} \\
\hline Baik & 33 & 86,8 & 5 & 13,2 & 38 & 100 & \\
\hline \multicolumn{8}{|l|}{ Jenis Kelamin } \\
\hline Perempuan & 3 & 100 & 0 & 0 & 3 & 100 & \multirow{2}{*}{0,499} \\
\hline Laki-Laki & 39 & 86,7 & 6 & 13,3 & 45 & 100 & \\
\hline \multicolumn{8}{|l|}{ Status Ekonomi } \\
\hline$>$ Rp1.500.000 & 29 & 60,4 & 4 & 8,3 & 33 & 68,7 & \\
\hline$<\mathrm{Rp} 1.500 .000$ & 13 & 27,1 & 2 & 4,2 & 15 & 31,3 & 0,906 \\
\hline
\end{tabular}

Polri memperlihatkan bahwa pemakai narkotika dan minuman keras di Indonesia secara nasional terbanyak dari golongan pelajar, baik SLTP, SLTA, maupun mahasiswa, yang jumlahnya mencapai $70 \%$, sedangkan yang lulusan SD hanya $30 \%$ dan sebagian besar dari mereka berasal dari golongan menengah ke atas (Santrock, 2013) dan sejalan juga dengan hasil penelitian dari Dwi Agus Suseno dkk mengenai perilaku mengkonsumsi minuman keras di kalangan remaja awal (2014) memperlihatkan sebagian besar subyek penelitian mengatakan bahwa pertama kali minum minuman keras yaitu pada saat duduk di kelas VII MTs. 
Namun ada juga pertama kali minum minuman keras pada saat duduk di kelas VI SD. Notoadmojo (2005) menyatakan bahwa faktor yang dapat mempengaruhi tingkat pengetahuan adalah pendidikan, umur, pengalaman. Semakin tinggi tingkat pendidikan seseorang akan berpengaruh pada pengetahuannya. Jenjang pendidikan dalam penelitian ini adalah jenjang pendidikan saat pertama kali remaja mengkonsumsi sopi.

Responden yang tidak mempunyai kebiasaan mengkonsumsi soro saat berkumpul dengan teman sebanyak $72,7 \%$ namun mereka tetap mengkonsumsi soro. Sedangkan responden yang biasa mengkonsumsi soro jika bersama dengan teman sebesar 54,2\%. Hal ini didukung dengan hasil uji Chi-Square yang menunjukan bahwa ada hubungan antara faktor tradisi dengan konsumsi soro $(\mathrm{p}<0,05 ; \mathrm{p}=0,004)$. Hasil penelitian ini sejalan dengan sukma mardiyah panggabean mengenai analisis konsumsi tuak pada peminum tuak (2015) dengan hasil penelitian menunjukkan bahwa faktor tradisi perilaku konsumsi tuak sebanyak (96,7\%). Puspitawati (2004) menyebutkan beberapa remaja terjerumus dalam masalah minuman keras karena adanya ajakan atau tawaran dari teman serta banyaknya film dan sarana hiburan yang memberikan contoh model pergaulan moderen, biasanya mendorong remaja minum-minuman keras secara berkelompok.

Responden yang tidak menerima atau mempercayai dalam mengkonsumsi soro sebanyak 58,3\%. Sedangkan responden yang menerima atau mempercayai dalam mengkonsumsi soro sebanyak 97,2\%. Hal ini didukung dengan uji ChiSquare menunjukan bahwa ada hubungan yang signifikan $(\mathrm{p}<0,05 ; \mathrm{p}=0,000)$ antara faktor kepercayaan dengan konsumsi sopi. Hasil penelitian ini setara dengan Dwi Agus Suseno, dkk perilaku mengkonsumsi minuman keras di kalangan remaja awal (2014) dimana hasil penelitian menunjukan bahwa alasan remaja tersebut minum adalah karena ingin tahu, supaya dianggap seperti preman, gaul dan percaya diri. Penelitian ini juga sejalan dengan Miftahul J, Shanti R, Arsyad R. aspek sosial budaya pada konsumsi minuman beralkohol (tuak) (2014) dimana tuak merupakan minuman yang dapat mempererat persaudaraan dan selalu disajikan dalam perayaan pesta adat, sejalan juga dengan sukma mardiyah panggabean mengenai analisis konsumsi tuak pada peminum tuak (2015) dimana hasil penelitian menunjukan peminum tuak mempercayai khasiat tuak dapat 
meringankan keletihan mereka setelah bekerja dan sejalan juga dengan penelitian Dr. Tamsil Muis, perilaku mengkonsumsi minuman beralkohol pada mahasiswa (2013) dimana sebanyak 27 mahasiswa (69\%) untuk menghilangkan stress. Menurut Fukuyama (1995), menyatakan bahwa kepercayaan adalah pengharapan yang muncul dalam sebuah komunitas yang berperilaku normal, jujur, dan kooperatif berdasarkan norma-norma yang dimiliki bersama, demi kepentingan anggota yang lain dari komunitas itu.

Hasil dari sikap menunjukan bahwa sebanyak 90\% responden memiliki sikap kurang baik sedangkan $86,8 \%$ memiliki sikap yang baik. Hasil uji ChiSquare menunjukan bahwa tidak ada hubungan antara faktor sikap dengan konsumsi soro $(p>0,05 ; p=0,788)$. Hasil peneletian ini tidak sejalan dengan Sukma Mardiyah Panggabean, analisis konsumsi tuak pada peminum tuak (2015) dimana hasil penelitian lebih banyak memiliki sikap negatif terkait konsumsi tuak $(69,7 \%)$. Heri Purwanto dalam Wawan (2010) menyatakan bahwa sikap adalah pandangan-pandangan atau perasaan yang disertai kecenderungan untuk bertindak sesuai sikap objek tadi. Menurut Notoatmodjo dalam Wawan (2010) sikap merupakan reaksi atau respon seseorang yang masih tertutup terhadap suatu stimulus atau objek (Wawan, 2010).

Sebanyak $100 \%$ responden berjenis kelamin perempuan dan $86,7 \%$ berjenis kelamin laki-laki. Hasil uji Chi-Square menunjukan bahwa tidak ada hubungan antara faktor jenis kelamin dengan konsumsi soro ( $>00,05 ; \mathrm{p}=0,499)$. Hasil penelitian ini tidak sejalan dengan Citra Septyaningrum, faktor-faktor yang mempengaruhi perilaku remaja usia 16-20 tahun minum miras (minuman keras) (2013) dengan hasil penelitian 43,6\% faktor jenis kelamin cukup mempengaruhi. Gender merupakan suatu konsep kultural yang berupaya membuat pembedaan (distinction) dalam hal peran, perilaku, mentalitas dan karakteristik emosional antara laki-laki dan perempuan yang berkembang dalam masyarakat. Gender merujuk pada peranan dan tanggung jawab laki-laki dan perempuan yang diciptakan dalam keluarga, masyarakat dan budaya (UNESCO, 2007).

Orang tua remaja yang berpenghasilan >Rp1.500.000/bulan sebanyak $60,4 \%$ dan yang berpenghasilan $<$ Rp1.500.000/bulan sebanyak 27,1\%. Hasil uji Chi-Square menunjukan bahwa tidak ada hubungan antara faktor status ekonomi dengan konsumsi soro $(\mathrm{p}>0,05 ; \mathrm{p}=0,906)$. Hasil penelitian ini sejalan dengan Desi 
Maria Ulfah, faktor-faktor penggunaan minuman keras di kalangan remaja (2005) dengan hasil penelitian kalangan remaja yang sering minum-minuman keras berasal dari keluarga ekonomi menengah, oleh karena itu dalam minum-minuman keras dengan cara patungan dan

sejalan dengan Miftahul J. dkk. aspek sosial budaya pada konsumsi minuman beralkohol (tuak) (2014) dimana hasil penelitian status sosial ekonomi tinggi biasanya menyediakan bir di setiap acaranya. Soetjiningsih (2004) menyatakan bahwa status sosial ekonomi merupakan gambaran tentang keadaan seseorang atau suatu masyarakat yang ditinjau dari segi sosial ekonomi, gambaran itu seperti tingkat pendidikan, pendapatan dan sebagainya. Status ekonomi kemungkinan besar merupakan pembentuk gaya hidup keluarga. Pendapatan keluarga memadai akan menunjang tumbuh kembang anak. Karena orang tua dapat menyediakan semua kebutuhan anak baik primer maupun skunder.

\section{Faktor Pemungkin (Jarak, Harga, Pemasaran dan Orang Tua)}

Hasil penelitian menunjukan bahwa 100\% responden menempuh jarak pembelian soro $>1 \mathrm{~km}$ sedangkan $23,1 \%$ responden tidak mengkonsumsi soro. Hal ini didukung dengan uji Chi-Square menunjukan bahwa ada hubungan antara faktor jarak dengan konsumsi soro $(\mathrm{p}<0,05 ; \mathrm{p}=0,016)$. Hasil penelitian ini sejalan dengan Mawaddah Tsaniyah Perilaku Minum Cuka (Minuman Beralkohol Tradisional) Pada Remaja (2009) dengan hasil penelitian cuka erat kaitannya dengan tradisi margondang dan acara keramaian dan bisa didapat dengan mudah. Keterjangkauan atau akses artinya ketersedian yang harus dapat dicapai oleh masyarakat, tidak terhalang oleh keadaan geografis. Jika jarak suatu tempat berdekatan dengan tempat lainnya, dikatakan aksesibilitas antara kedua tempat tersebut tinggi. Sebaliknya jika berjauhan aksesibilitas antara keduanya rendah. Jika antar kedua tempat memiliki waktu tempuh yang cepat maka dapat dikatakan kedua tempat itu memiliki aksesibilitas yang tinggi (Tamin, 2000).

Responden yang membeli soro dengan harga per botol >Rp15.000 sebanyak 91,4\% dan sebanyak $23,1 \%$ responden tidak mengkonsumsi soro. Hasil uji ChiSquare menunjukan bahwa tidak ada hubungan $(\mathrm{p}<0,05 ; \mathrm{p}=0,177)$ antara faktor harga dengan konsumsi soro. Hasil Penelitian ini sejalan dengan Dwi Agus Suseno, dkk. Perilaku Mengkonsumsi Minuman Keras Di Kalangan Remaja Awal 
(2014) dengan hasil penelitian harga miras di desa sangat terjangkau sehingga remaja banyak yang membelinya karena harganya sekitar 30 ribu sampai 50 ribu.

Tabel 3. Hubungan Faktor Pemungkin (Jarak, Harga, Pemasaran dan Orang Tua) Dengan Konsumsi Soro

\begin{tabular}{|c|c|c|c|c|c|c|c|}
\hline \multirow{3}{*}{ Faktor Pemungkin } & \multicolumn{6}{|c|}{ Konsumsi Soro } & \multirow{3}{*}{$p$ (Value) } \\
\hline & \multicolumn{2}{|c|}{ Ya } & \multicolumn{2}{|c|}{ Tidak } & \multicolumn{2}{|c|}{ Total } & \\
\hline & $\mathbf{n}$ & $\%$ & $\mathbf{N}$ & $\%$ & $\mathbf{n}$ & $\%$ & \\
\hline \multicolumn{8}{|l|}{ Jarak } \\
\hline Dekat & 20 & 76,9 & 6 & $23,1 \%$ & 26 & 100 & \multirow{2}{*}{0,016} \\
\hline Jauh & 22 & 100 & 0 & 0 & 22 & 100 & \\
\hline \multicolumn{8}{|l|}{ Harga } \\
\hline Mahal & 32 & 91,4 & 3 & 8,6 & 35 & 100 & \multirow{2}{*}{0,177} \\
\hline Murah & 10 & 76,9 & 3 & 23,1 & 13 & 100 & \\
\hline \multicolumn{8}{|l|}{ Pemasaran } \\
\hline Tidak & 4 & 50 & 4 & 50 & 8 & 100 & \multirow{2}{*}{0,000} \\
\hline $\mathrm{Ya}$ & 38 & 95 & 2 & 5 & 40 & 100 & \\
\hline \multicolumn{8}{|l|}{ Dukungan Orang Tua } \\
\hline Tidak & 11 & 64,7 & 6 & 35,3 & 17 & 100 & \multirow{2}{*}{0,000} \\
\hline $\mathrm{Ya}$ & 31 & 100 & 0 & 0 & 31 & 100 & \\
\hline \multicolumn{8}{|l|}{ Dukungan Lingkungan } \\
\hline Tidak & 1 & 25 & 3 & 75 & 4 & 100 & \multirow{2}{*}{0,000} \\
\hline $\mathrm{Ya}$ & 41 & 93,2 & 3 & 6,8 & 44 & 100 & \\
\hline
\end{tabular}

Basu Swastha \& Irawan (2005) menyatakan bahwa harga ialah sesuatu yang dibutuhkan untuk mendapatkan suatu kombinasi antara pelayanan ditambah produk dengan membayar jumlah uang yang sudah menjadi patokan. Buchari Alma (2002) harga merupakan sebuah nilai yang ditentukan untuk suatu barang maupun jasa yang ditentukan dengan uang. Henry Simamora (2002) harga ialah nilai uang yang harus dikeluarkan untuk mendapatkan produk atau jasa yang diinginkan.

Tempat penjualan soro yang terdapat di sekitar tempat tinggal remaja sebanyak 95\%. Hal ini didukung dengan uji Chi-Square menunjukan bahwa ada hubungan antara faktor pemasaran dengan konsumsi soro $(\mathrm{p}<0,05 ; \mathrm{p}=0,000)$. Hasil penelitian ini sejalan dengan Gero S. model pelayanan kesehatan pencegahan primer peminum "moke" dengan pendekatan tanscultural care (2013) dengan hasil penelitian faktor ketersediaan 'moke" $(\mathrm{r}=0,412)$. Pemasaran adalah semua kegiatan yang bertujuan untuk memperlancar arus barang atau jasa dari 
produsen ke konsumen secara paling efisien dengan maksud untuk menciptakan permintaan efektif (Hasyim, 1994).

Orang tua remaja yang tidak mengkonsumsi soro sebanyak 64,7\% sedangkan $100 \%$ orang tua remaja yang mengkonsumsi soro. Hal ini didukung dengan uji Chi-Square menunjukan bahwa terdapat hubungan signifikan antara faktor dukungan orang tua dengan konsumsi soro $(\mathrm{p}<0,05 ; \mathrm{p}=0,000)$. Hasil penelitian sejalan dengan Sukma Mardiyah Panggabean, analisis konsumsi tuak pada peminum tuak (2015) dimana hasil penelitian sebagian besar $(76,2 \%)$ keluarga peminum tuak masih memiliki kebiasaan mengonsumsi tuak. Gunarsa (1976) menyatakan bahwa orang tua adalah dua individu yang berbeda memasuki hidup bersama dengan membawa pandangan, pendapat dan kebiasaan- kebiasaan sehari-hari." Dalam hidup berumah tanggga tentunya ada perbedaan antara suami dan istri, perbedaan dari pola pikir, perbedaan dari gaya dan kebiasaan, perbedaan dari sifat dan tabiat, perbedaan dari tingkatan ekonomi dan pendidikan, serta banyak lagi perbedaan-perbedaan lainya. Perbedaan-perbedaan inilah yang dapat mempengaruhi gaya hidup anak-anaknya, sehingga akan memberikan warna tersendiri dalam keluarga. Perpaduan dari kedua perbedaan yang terdapat pada kedua orang tua ini akan mempengaruhi kepada anak-anak yang dilahirkan dalam keluarga tersebut.

Hasil dari teman terdekat remaja yang juga mengkonsumsi soro sebanyak 93,2\%. Hasil uji Chi-Square menunjukan bahwa ada hubungan $(\mathrm{p}<0,05 ; \mathrm{p}=0,000)$ antara faktor dukungan lingkungan dengan konsumsi soro. Hasil penelitian ini sejalan dengan Citra Septyaningrum, faktor-faktor yang mempengaruhi perilaku remaja usia 16-20 tahun minum miras (minuman keras) (2013) dengan hasil penelitian faktor pengaruh teman sebaya mempengaruhi perilaku remaja usia 1620 tahun minum miras, sejalan juga dengan Mawaddah Tsaniyah, perilaku minum cuka (minuman beralkohol tradisional) pada remaja (2009) dengan hasil penelitian remaja biasanya minum cuka 3-4 kali seminggu, dilakukan bersama teman-teman pada malam hari di gubuk-gubuk kosong, sejalan juga dengan Dr. Tamsil Muis Perilaku, mengkonsumsi minuman beralkohol pada mahasiswa (2013) dengan hasil penelitian sebanyak 31 mahasiswa (84\%) mengenal minuman beralkohol dari film-film di televisi dan sejalan dengan Desi Maria ulfah faktorfaktor penggunaan minuman keras di kalangan remaja (2005) dengan hasil 
penelitian remaja minum minuman keras karena lingkungan yang mendukung. Piaget dan Sullivan (dalam Santrock 2007) menekankan bahwa melalui interaksi dengan teman-teman sebaya, anak-anak dan remaja mempelajari modus relasi yang timbal balik secara simetris. Anak-anak mengeksplorasi prinsip-prinsip kesetaraan dan keadilan melalui pengalaman mereka ketika menghadapi perbedaan pendapat dengan teman-teman sebaya. Sebaliknya, pengaruh negatif dari teman-teman sebaya bagi perkembangan anak dan remaja. Bagi beberapa remaja, pengalaman ditolak atau diabaikan dapat membuat mereka merasa kesepian dan bersikap bermusuhan.

\section{Faktor Penguat (Pergaulan dan Kontrol Orang Tua)}

Hasil penelitian menunjukan bahwa $80,6 \%$ teman terdekat tidak menegur/menasehati ketika melihat remaja mengkonsumsi soro. Hasil uji ChiSquare menunjukan bahwa ada hubungan $(\mathrm{p}<0,05 ; \mathrm{p}=0,052)$ antara faktor pergaulan dengan konsumsi soro. Hasil penelitian ini sejalan dengan Deby P. hubungan antara konformitas kelompok dengan perilaku minum minuman keras pada remaja (2011) dengan hasil analisis statistik spearman's menunjukan level signifikasi $\square=0,05$ menghasil nilai $\mathrm{p}=0,000$ sehingga $\mathrm{p}<0,05$ dimana ada hubungan yang signifikan antara konformitas kelompok dengan perilaku minum minuman keras pada remaja. Basrowi (2005) menyatakan bahwa pergaulan tidak dapat dilepaskan dari interaksi yaitu hubungan yang dinamis antar individu dengan individu lainnya, individu dengan kelompok serta kelompok dengan kelompok lainnya.

Tabel 4. Hubungan Faktor Penguat (Pergaulan dan Kontrol Orang Tua) Dengan Konsumsi Soro

\begin{tabular}{|c|c|c|c|c|c|c|c|}
\hline \multirow{3}{*}{ Faktor Penguat } & \multicolumn{6}{|c|}{ Konsumsi Soro } & \multirow{3}{*}{$p$ (Value $)$} \\
\hline & \multicolumn{2}{|c|}{ Ya } & \multicolumn{2}{|c|}{ Tidak } & \multicolumn{2}{|c|}{ Total } & \\
\hline & $\mathbf{n}$ & $\%$ & $\mathbf{n}$ & $\%$ & $\mathbf{n}$ & $\%$ & \\
\hline \multicolumn{8}{|l|}{ Pergaulan } \\
\hline Tidak & 25 & 80,6 & 6 & 19,4 & 31 & 100 & 0,052 \\
\hline $\mathrm{Ya}$ & 17 & 100 & 0 & 0 & 17 & 100 & \\
\hline \multicolumn{8}{|l|}{ Kontrol Orang Tua } \\
\hline Tidak & 6 & 50 & 6 & 50 & 12 & 100 & 0,000 \\
\hline $\mathrm{Ya}$ & 36 & 100 & 0 & 0 & 36 & 100 & \\
\hline
\end{tabular}


Hasil dari kontrol orang tua sebanyak 50\% responden menyatakan orang tuanya tidak menegur/menasehati ketika melihat remaja mengkonsumsi soro sedangkan $100 \%$ orang tua menegur/menasehati ketika melihat remaja mengkonsumsi soro. Hal ini didukung dengan uji Chi-Square menunjukan bahwa ada hubungan antara faktor kontrol orang tua dengan konsumsi soro $(\mathrm{p}<0,05$; $\mathrm{p}=0,000)$. Hasil penelitian ini sejalan dengan Amirul Amalia, peran orang tua terhadap konsumsi alkohol pada remaja putra (2015) dari hasil penelitian didapatkan hampir sebagian atau $34,8 \%$ peran orang tua kurang, dan lebih dari sebagian atau $63 \%$ mengonsumsi alkohol tingkat rendah, terdapat hubungan antara peran orang tua dengan konsumsi alkohol pada remaja putra Nilai rs $=0,749$ dan $p=0,000$. Latifah (2008) pola interaksi antara anak dengan orang tua meliputi pemenuhan kebutuhan fisik (seperti makan, minum dan lain-lain) dan kebutuhan psikologis (seperti rasa aman, kasih sayang, perlindungan, dan lain-lain), serta sosialisasi norma-norma yang berlaku dimasyarakat agar anak dapat hidup selaras dengan lingkungannya. Dengan kata lain, pola asuh juga meliputi pola interaksi orang tua dengan anak dalam pendidikan karakter anak.

\section{PENUTUP}

Berdasarkan hasil penelitian dan pembahasan, maka dapat disimpulkan bahwa pada faktor predisposisi (pengetahuan, pendidikan, tradisi, kepercayaan, umur, jenis kelamin dan sikap) dengan konsumsi soro.; ada hubungan antara faktor pengetahuan dengan konsumsi soro pada remaja di Kelurahan Liliba Kota Kupang, ada hubungan antara faktor jenjang pendidikan dengan konsumsi soro pada remaja di Kelurahan Liliba Kota Kupang, ada hubungan antara faktor tradisi dengan konsumsi soro pada remaja di Kelurahan Liliba Kota Kupang, ada hubungan antara faktor kepercayaan dengan konsumsi soro pada remaja di Kelurahan Liliba Kota Kupang, tidak ada hubungan antara faktor sikap dengan konsumsi soro pada remaja di Kelurahan Liliba Kota Kupang, tidak ada hubungan antara faktor jenis kelamin dengan konsumsi soro pada remaja di Kelurahan Liliba Kota Kupang dan tidak ada hubungan antara faktor status sosial dengan konsumsi soro pada remaja di Kelurahan Liliba Kota Kupang.

Faktor pendukung (jarak, harga, pemasaran, dukungan orang tua dan dukungan lingkungan) dengan konsumsi soro; tidak ada hubungan antara faktor harga dengan konsumsi soro pada remaja di Kelurahan Liliba Kota Kupang, tidak ada hubungan antara 
faktor pemasaran dengan konsumsi soro pada remaja di Kelurahan Liliba Kota Kupang, ada hubungan antara faktor dukungan orang tua dengan konsumsi soro pada remaja di Kelurahan Liliba Kota Kupang dan ada hubungan antara faktor dukungan lingkungan dengan konsumsi soro pada remaja di Kelurahan Liliba Kota Kupang

Faktor penguat (pergaulan dan kontrol orang tua) dengan konsumsi soro; ada hubungan antara faktor pergaulan dengan konsumsi soro pada remaja di Kelurahan Liliba Kota Kupang dan ada hubungan antara faktor kontrol orang tua dengan konsumsi soro pada remaja di Kelurahan Liliba Kota Kupang

Faktor yang paling berhubungan terhadap konsumsi soro pada remaja di Kelurahan Liliba Kota Kupang adalah faktor kepercayaan dimana setiap penurunan 1 unit kepercayaan akan menurunkan konsumsi soro pada remaja di Kelurahan Liliba Kota Kupang sebesar 3,081.

\section{DAFTAR PUSTAKA}

Ahmadi. 2003. Tentang Sikap yang Tercermin dari Perilaku. Rineka Cipta:Jakarta.

Amirul Amalia. 2015. Peran Orang Tua Terhadap Konsumsi Alkohol Pada Remaja Putra Desa Sidoarjo Kecamatan Sugio Kabupaten Lamongan.https://www.google.co.id/\#q=Amirul+Amalia+(2015)+Peran+Oran g+Tua+Terhadap+Konsumsi+Alkohol+Pada+Remaja+Putra+Desa+Sidoarjo+ Kecamatan+Sugio+Kabupaten+Lamongan. (diakses pada tanggal 22 September 2016).

Anonim. 2011. Menyedihkan, Kupang Rangking Ketiga Pengkonsumsi Miras. http: //www. voa-islam . com /news/indonesiana/2011/11/23/ 1679/ menyedihkankupang-rangking-ketiga-pengkonsumsi-miras/ (diakses pada tanggal 22 September 2016).

Anonim. 2012. Dampak Negatif Minuman Keras. (diakses pada tanggal 22 September 2016)

Anonim. 2013. Pengertian dan ciri-ciri remaja. http: // blogsiputri. Blogspot .com /2013/02/ pengertian-dan-ciri-ciri-remaja_28.html (diakses pada tanggal 22 September 2016)

Anggraini,Rika.2012.Perkembangan Nilai Moral, dan Sikap. Palembang.

Arikunto. S. 2006 Prosedur Penelitian suatu Pendekatan Praktik. Jakarta : PT Rineka Cipta.

Astri, A. 2012. Sopi, Yang Membuai dari Timur. http://intisari-online.com/read / sopi yang - membuai - dari -timur. (diakses pada tanggal 22 September 2016).

Badan Narkotika Nasional (BNN), 2011. Anti Drungs Campaign Goes to School. Jakarta: BNN.

Chandra, Budiman. 2008. Metodologi Penel itian Kesehatan. EGC. Jakarta.

Citra S. 2013. Faktor-faktor yang Mempengaru hi Perilaku Remaja Usia 16-20 Tahun Minum Miras (Minuman Keras) RT 10 RW 01 Kelurahan Dukuh Setro Kecamatan Tambaksari Surabaya. http://akper-adihusada.ac.id/ 
perpustakaan/detailkti.php?idbook= 1124\&kol eks $\mathrm{i}=$ active. (diakses pada tanggal 22 September 2016).

Desi M. Ulfah, 2005. Faktor-Faktor Pengg unaan Minuman Keras Di Kalangan Remaja Di Desa Losari Kecamatan Rembang Kabupaten Purbalingga.

Deby P, 2011. Hubungan Antara Konformitas Kelompok Dengan Perilaku Minum Minuman Keras Pada Remaja. Dusun Jagalan Margodadi Seyegan Sleman Yogyakarta. (diakses pada tanggal 22 September 2016).

Dwi A.S, Eti .R, Nurjanah. 2014. Perilaku Mengkonsumsi Minuman Keras Di Kalangan Remaja Awal Di Desa Kunden Kecamatan Wirosari Kabupaten Grobogan

Dinas Kesehatan Provinsi NTT, 2014. Profil Kesehatan Provinsi Nusa Tenggara Timur tahun 2014, Kupang.

Direktorat Bina Pelayanan Kesehatan Jiwa, Dirjen Bina Pelayanan Medik Kepmenkes RI, 2010. Kemenkes RI No. 422/Menkes/SK/III/2010 Tentang Pedoman Penatalaksanaan Medik Gangguan Penggunaan NAPZA. Jakarta

Dominggu Elcid Li. 2013. Industri Sopi di NTT Yang Berkelanjutan (Towards the sustainability of NTT Sopi).

Dr. Tamsil Muis. 2013. Perilaku Mengkonsumsi Minuman Beralkohol Pada Mahasiswa Fakultas Ilmu Pendidikan Universitas Negeri Surabaya.. (diakses pada tanggal 22 September 2016)

Dwi A. S, Eti R, Nurjanah. 2014. Perilaku Mengkonsumsi Minuman Keras Di Kalangan Remaja Awal Desa Kunden Kecamatan Wirosari Kabupaten Grobogan. (diakses pada tanggal 22 September 2016)

Geldard, Kathryn \& David Geldard. 2010. Konseling Remaja Pendekatan Proaktif untuk Anak Muda (Eka Adinugraha, Penerjemah). Pustaka Pelajar: Yogyakarta.

Gero, S. 2013. Model Pelayanan Kesehatan Pencegahan Primer Peminum 'Moke' Dengan Pendekatan Transcultural Care di Masyarakat Sikka, Provinsi NTT.

Hamsir. 2012. Perkembangan Moral, dan Sikap Remaja.Bulukumba. http: // hamsir-amunk.blogspot.com. (diakses pada tanggal 22 September 2016)

Hasan S.M. 2008. Studi Tentang Dampak Minuman Keras Di Kelurahan Dembe II Kecamatan Kota Utara Kota Gorontalo. documents/ pengaruhpenggunaan-minuman-keras-pada-kehidupanremaja. Html. (diakses pada tanggal 22 September 2016)

Hidayat, Alimul Aziz A. 2009. Metode Penelitian Keperawatan dan Teknik Analisa Data. Jakarta: Salemba Medika.

Hurlock, E. B. 2012. Psikologi Perkembangan: Suatu Pendekatan Sepanjang Rentang Kehidupan (Alih Bahasa Istiwidayanti, dkk). Edisi Kelima. Jakarta: Erlangga

Kasat Res Narkoba, 2016. Laporan Hasil Pelaksanaan Tugas, Sat Narkoba, Kota Kupang.

Kasiha N. 2007. Pengetahuan Remaja Tentang Dampak Mengkonsumsi Minuman Keras Didesa Titidu Kecamatan Kwandang Kabupaten Gorontalo Utara. http://zaghipocker.blogspot.co.id/2009/05/proposal-tentangpenggunaanmiras-di.html. (diakses pada tanggal 22 September 2016)

Li ,E. D., Rohi, R., Mali, R. L., Ndoen, E., Mesakh, M., Talan, J. P. 2013. Industrialisasi Sopi di NTT yang Berkelanjutan (Towards the sustainability of NTT Sopi). IRGSC Policy Brief No 001. Research and 
analysis from the Institute of Resource Governance and Social Change (IRGSC) www.irgsc.org

Mawaddah Tsaniyah. 2009. Perilaku Minum Cuka (Minuman Beralkohol Tradisional) Pada Remaja Di Kecamatan Padang Bolak Kabupaten Padang Lawas Utara. http://etd.repository.ugm.ac.id/index. php?act= view\&buku_id=58411 $\&$ mod=penelitian_detail\&sub=PenelitianDetail\&typ=html. (diakses pada tanggal 22 September 2016)

Nursalam. 2008. Konsep dan Penerapan Metodologi Penelitian : Pedoman Skripsi, Tesis dan Instrumen Penelitian Keperawatan. Ed. 5. Jakarta: Salemba Medika.

Patrick, M., Maggs, J. L. 2013. Energy Drinks and Alcohol: Links to Alcohol Behaviors and Consequences Across 56 Days. Society for Adolescent Health and Medicine. All rights reserved:Pennsylvania

Sarwono, Sarlito W. 2012. Psikologi Remaja. Jakarta: Raja Grafindo Persada.

Setiadi. 2007. Konsep dan Penulisan Riset Keperawatan. Yogyakarta: Graha Ilmu.

Sugiyono. 2011. Metode Penelitian Pendidikan. Bandung: Alfabeta

Utarini, A. 2014. Modul Mata Kuliah :

Metode Penelitian Kualitatif. Magister Perilaku dan Promosi Kesehatan, program studi Ilmu Kesehatan Masyarakat. UGM.Yogyakarta 